Research Paper

\title{
Impact of Intercellular Adhesion Molecule-1 Genetic Polymorphisms on Coronary Artery Disease Susceptibility in Taiwanese Subjects
}

\author{
Chi-Hung Chou ${ }^{1,2}$, Kwo-Chang Ueng ${ }^{3,4}$, Yu-Fan Liu ${ }^{5}$,Chih-Hsien Wu11, Shun-Fa Yang1,6, Po-Hui Wang1,4,7, \\ 1. Institute of Medicine, Chung Shan Medical University,110, Section 1, Chien-Kuo North Road, Taichung, 40201, Taiwan \\ 2. Division of Cardiology, Department of Internal Medicine, Yuan-Sheng Hospital and Changhua Christian Hospital, Yuanlin Branch, Yuanlin, \\ Taiwan \\ 3. Department of Internal Medicine, Chung Shan Medical University Hospital, 110, Section 1, Chien-Kuo North Road, Taichung, 40201, Taiwan \\ 4. School of Medicine, Chung Shan Medical University, Taichung, Taiwan \\ 5. Department of Biomedical Sciences, Chung Shan Medical University, Taichung, Taiwan \\ 6. Department of Medical Research, Chung Shan Medical University Hospital, Taichung, 40201, Taiwan \\ 7. Department of Obstetrics and Gynecology, Chung Shan Medical University Hospital, Taichung, Taiwan
}

$\square$ Corresponding author: Po-Hui Wang, M.D., Ph.D., Institute of Medicine, Chung Shan Medical University, Department of Obstetrics and Gynecology, Chung Shan Medical University Hospital,110, Section 1, Chien-Kuo North Road, Taichung, 40201, Taiwan. Tel.: 886-4-24739595 ext. 21721; Fax: 886-4-24738493; E-mail: wang082160@yahoo.com.tw

() 2015 Ivyspring International Publisher. Reproduction is permitted for personal, noncommercial use, provided that the article is in whole, unmodified, and properly cited. See http://ivyspring.com/terms for terms and conditions.

Received: 2015.03.11; Accepted: 2015.05.25; Published: 2015.06.09

\begin{abstract}
The principal pathogenesis of coronary artery disease (CAD) is coronary artery atherosclerosis, a chronic inflammatory disease of the vessel walls of the coronary artery. Intercellular adhesion molecule-1 (ICAM-1) displays an important role in the development of the inflammation reaction and atherosclerosis. Few studies report the association of ICAM-1 genetic polymorphisms with CAD in Taiwanese subjects. Therefore, we conducted a study to associate the single nucleotide polymorphisms (SNPs) of ICAM-1, rs5491, rs5498, rs281432 and rs3093030 with CAD. Five hundred and twenty-five male and female subjects, who received elective coronary angiography in Taiwan Chung Shan Medical University Hospital, were recruited to determine four ICAM-1 SNPs by real time-polymerase chain reaction and genotyping. The relationships among ICAM-1 SNPs, haplotypes, demographic and characteristics and CAD were analyzed. This study showed that rs281432 (C8823G) was the only ICAM-1 SNP which affect the development of CAD. Multivariate analysis revealed that ICAM-1 SNP rs 281432 CC/CG [ $p=0.016$; odds ratio (OR): $2.56,95 \%$ confidence interval $(\mathrm{Cl})$ : 1.19-5.56], male gender ( $p=0.018$; OR: 1.66, 95\% Cl: 1.09-2.51), aspirin use in the past 7 days ( $p=0.001$; OR: $2.05,95 \% \mathrm{Cl}$ : 1.33-3.14), hypertension ( $p<0.001$; OR: $2.15,95 \% \mathrm{Cl}$ : 1.42-3.25), serum cardiac troponin I elevation ( $p<0.001$; OR: $2.14,95 \% \mathrm{Cl}: 1.47-3.24$ ) and severe angina in recent 24 hours ( $p=0.001$; OR: $1.97,95 \% \mathrm{Cl}$ : 1.31-2.95) increase the risk of CAD. In conclusion, ICAM-1 SNP rs281432 is an independent factor to predict the development of CAD. ICAM-1 SNP rs281432 homozygotic mutant GG can reduce the susceptibility to the CAD in Taiwanese subjects.
\end{abstract}

Key words: Coronary artery disease, genetic polymorphism, haplotype, intercellular adhesion molecule-1, rs281432, Taiwanese.

\section{Introduction}

Heart disease, just after cancer the first in the rank, was the second leading cause of death in recent years in Taiwan. Based on the World Health Organization classification, coronary artery disease (CAD) is the partial or total loss of the vascular supply to the myocardium [1].The principal pathogenesis of CAD is coronary artery atherosclerosis, which is a chronic inflammatory disease of the vessel walls of the coro- 
nary artery where monocytes and macrophages accumulate during the initial phase of atherosclerosis [2]. The risk factors of CAD include conventional and nonconventional factors $[3,4]$. The conventional risk factors include male gender, hypertension, smoking, diabetes mellitus and high serum cholesterol $[1,4,5]$. Coronary artery disease may be determined by specific genetic polymorphic variants, the nonconventional factors, which affect the production of protein involved in the atherosclerotic processes. Adhesion molecules are one of the important markers of endothelial dysfunction [6].

The Intercellular adhesion molecule-I (ICAM-1) gene is located on chromosome 19, and includes 7 exons and 6 introns that code a 90-kDa transmembrane glycoprotein. The protein belongs to the immunoglobulin superfamily of adhesion molecules and consists of five extracellular Ig-like domains, a transmembrane domain, and a short cytoplasmic tail $[7,8]$. It mediates adhesion of circulating leukocytes to the blood vessel wall and activated endothelium as well as the transendothelial migration to the vascular intima, which are important pathogeneic processes of atherosclerosis $[9,10]$. ICAM-1 displays an important role in the development of the inflammation reaction, atherosclerosis, and thrombosis [11].

Genetic variants in ICAM-1 gene have been shown to regulate the expression level and have been widely studied for possible genetic association with a range of degenerative and inflammatory diseases [12-14]. A common genetic polymorphism of the ICAM-1 gene, rs5498 (A1548G in exon 6) results the substitution of lysine to glutamate (K469E) and has possible functional value in the etiology of atherosclerosis [15]. Previous studies have revealed that polymorphic variations in exon 6 (rs5498), exon 2 (rs5491, K56M) or intron 2 (rs281432, C8823G) and in the region between the ICAM-1 and ICAM-4 genes (rs3093030, C-286T) are associated with risks of diabetes mellulitis, metabolic syndrome, systemic lupus erythematosus and cancers [13, 16-18]. To date, few studies report the association of ICAM-1 genetic polymorphisms with CAD in Taiwan. Therefore, we conducted a study to investigate the association of the single nucleotide polymorphisms (SNPs) of ICAM-1, rs5491, rs5498, rs281432 and rs3093030) with CAD.

\section{Material and Methods}

\section{Subjects}

Five hundred and twenty-five unrelated male and female subjects who received elective coronary angiography in Chung Shan Medical University Hospital were recruited between the years 2005 and 2009. The included subjects for doing elective coro- nary angiography were those who had positive noninvasive tests such as the treadmill test, myocardial perfusion scan, or cardiac computed tomography scan. The exclusion criteria included patient refusal, known cerebrovascular attack history, peripheral arterial disease, and incomplete data. The diagnostic gold standard of CAD was defined as more than $50 \%$ stenosis over any segment of the coronary artery by angiography.

The demographic characteristics were recorded, including gender, age, body length, body weight, systolic pressure, diastolic pressure, body mass index, family history and smoking. The clinical characteristics and risk factors were also recorded, including male gender, age $>65$ years, active smoker, hypertension, diabetic mellitus, aspirin use in the past 7 days and hypercholesterolemia. Active smoker were referred to as a person who currently smoked at least one pack of cigarettes/day. Hypertension was defined as systolic and/or diastolic blood pressure above 140/90 $\mathrm{mmHg}$ [19] or the studied subjects were receiving anti-hypertensive treatment among the study period. The hypercholesterolemia was defined as serum cholesterol levels more than $200 \mathrm{mg} / \mathrm{dL}$ [20]. The individuals were determined whether they have more than 3 risk factors according to the male gender, age $>65$ years, active smoker, hypertension, diabetic mellitus, hypercholesterolemia etc. Cardiac marker elevation was known as the elevation of the serum cardiac troponin I level. The study was approved by the Institutional Review Board of Chung Shan Medical University Hospital (CSMUH No: CS07095), and informed consents were obtained from all participants.

\section{Blood sample collection and genomic DNA extraction}

In total, 525 blood specimens were collected from the subjects who received elective coronary angiography in Chung Shan Medical University Hospital. Genomic DNA was extracted from EDTA anti-coagulated venous blood using a QIAamp DNA blood mini kit (Qiagen, Valencia, CA, USA) based on the manufacturer's protocol. The DNA was dissolved in Tris ethylene buffer $(10 \mathrm{mmol} / \mathrm{L}$ Tris and 1 mmol/L EDTA; pH 7.8) and then quantified by a measurement of OD260. The final preparation was stored at $-20^{\circ} \mathrm{C}$ and applied as the template in polymerase chain reaction (PCR).

\section{Selection of intercellular adhesion molecule-1 gene polymorphisms}

Over 20 SNPs in the 7-exon region of the ICAM-1 gene have been documented based on the dbSNP database. This study involved the nonsynonymous 
SNPs rs5491 (K56M in exon 2) and rs5498 (A1548G in exon 6) in the coding sequences as well as rs281432 (C8823G in intron 2) of the gene based on the Chinese HapMap (Han Chinese in Beijing, China) data. Furthermore, another SNP between the ICAM-1 andICAM-4 genes (rs3093030, C-286T) was selected in this study since this SNP affected the production of sICAM-1 in a Chinese population [21]. Because rs5498 is in linkage disequilibrium with $\mathrm{rs} 3093030\left(\mathrm{R}^{2}=0.84\right)$ based on Chinese HapMap data, the haplotypes of rs5498 and rs3093030 was established and included into analysis.

\section{Single nucleotide polymorphisms by real time-PCR and genotyping}

Allelic discrimination of rs5491(K56M), rs5498 (A1548G), rs281432 (C8823G) and rs3093030 (C-286T) was assessed using an ABI StepOne ${ }^{\mathrm{TM}}$ Real-Time PCR System (Applied Biosystems, Foster City, CA, USA), and analyzed by SDS version 3.0 software (Applied Biosystems) using the TaqMan assay. The $10 \mu \mathrm{L}$ final volume for each reaction contained $5 \mu \mathrm{L}$ TaqMan Genotyping Master Mix, $0.25 \mu \mathrm{L}$ TaqMan probe mix, and $10 \mathrm{ng}$ genomic DNA. Real-time PCR included an initial denaturation step at $95^{\circ} \mathrm{C}$ for 10 minutes, followed by 40 cycles of $95^{\circ} \mathrm{C}$ for 15 seconds and then $60^{\circ} \mathrm{C}$ for one minute.

\section{Statistical analysis}

Hardy-Weinberg equilibrium was used to analyze the genotype distributions of rs3093030, rs5491, rs281432 and rs5498 in the negative CAD group [degree of freedom $(\mathrm{df})=2$ ]. Student $t$ or chi-square tests were used to analyze the association of demographic features and clinical variables with CAD. Chi-square and Fisher exact tests were used to examine the relationships of the frequencies of ICAM-1 gene SNPs and haplotypes with the incidence of CAD. The multiple comparisons were corrected by Bonferroni test for $p$ vaule. Multiple comparisons within 3 genotypes among each SNP and haplotype were adjusted using simple logistic regression model for the calculation of odds ratio (OR) and its 95\% confidence interval (95\% CI).

Logistic regression model was used to analyze the associations among ICAM1-1SNP, clinical characteristics and CAD for multivariate analysis. A significant difference was defined as a $p$ value of less than 0.05. All statistical analyses were performed using SPSS statistical software (version 11.0; SPSS, Inc., Chicago, IL). Statistical analyses including OR and adjusted odds ratio (AOR) and their 95\% CIs were calculated by the SPSS, version 12.0 and WinPepi Software, version 10.0.

\section{Results}

The demographic features of the studied subjects with and without CAD

The demographic features of the studied subjects are showed in Table 1 . There were no significant differences in age, body length, body weight, body mass index, systolic blood pressure and diastolic blood pressure between the patients with CAD and those without CAD. Only the gender exerted a significant difference between the male and female groups $(p=0.004)$.

Table 1. Demographic features of patients with coronary artery disease (CAD) and those without CAD.

\begin{tabular}{|c|c|c|c|}
\hline Demographic features & $\begin{array}{l}\text { Positive } \\
\text { CAD } \\
(\mathrm{N}=339)\end{array}$ & $\begin{array}{l}\text { Negative } \\
\text { CAD } \\
(\mathrm{N}=186)\end{array}$ & $p$ \\
\hline Gender & & & $0.004^{\mathrm{a}}$ \\
\hline Male & 251 & 115 & \\
\hline female & 88 & 71 & \\
\hline Age (years; mean $\pm \mathrm{SD}$ ) & $65.6 \pm 11.1$ & $66.1 \pm 12.0$ & 0.659 \\
\hline Body length (cm; mean $\pm S D)$ & $161.8 \pm 8.5$ & $160.6 \pm 8.8$ & 0.132 \\
\hline Body weight (kg; mean \pm SD) & $66.9 \pm 12.4$ & $65.0 \pm 13.2$ & 0.106 \\
\hline Body mass index $\left(\mathrm{kg} / \mathrm{m}^{2} ;\right.$ mean $\left.\pm \mathrm{SD}\right)$ & $25.5 \pm 4.4$ & $25.1 \pm 3.8$ & 0.238 \\
\hline $\begin{array}{l}\text { Systolic blood pressure }(\mathrm{mmHg} \\
\text { mean } \pm \mathrm{SD})\end{array}$ & $132.5 \pm 21.5$ & $129.9 \pm 19.7$ & 0.172 \\
\hline $\begin{array}{l}\text { Diastolic blood pressure }(\mathrm{mmHg} ; \\
\text { mean } \pm \mathrm{SD})\end{array}$ & $79.1 \pm 15.7$ & $77.2 \pm 14.4$ & 0.195 \\
\hline
\end{tabular}

\section{The association of clinical and risk variables with CAD}

The association of clinical characteristics with CAD was summarized in Table 2. The male gender was found to increase the risk of developing CAD ( $p=0.004$; OR: $1.76,95 \%$ CI: 1.18-2.63). Other factors which displayed the significantly elevated risks of CAD included: aspirin use in the past 7 days $(p=0.001$; OR: $1.99,95 \%$ CI: 1.31-3.05), hypertension $(p<0.001$; OR: $1.99,95 \%$ CI: 1.33 to 2.96$)$, diabetes mellitus $(p=0.034$; OR: $1.49,95 \%$ CI: 1.01-2.21), cardiac troponin I elevation ( $p<0.001$; OR: $2.26,95 \%$ CI: 1.54 to 3.31$)$, severe angina in the recent 24 hours $(p<0.001$; OR: 1.97, 95\% CI: $1.33-2.90)$ and $>3$ risk factors $(p=0.017$; OR: 1.55, 95\% CI: 1.06-2.26) (Table 2).

\section{The association of ICAM-1 polymorphisms with CAD}

The genotypic distributions of ICAM-1 SNPs in the subjects with CAD and without CAD are summarized in Table 3. The genotypic frequency of ICAM-1 SNP rs281432 met the Hardy-Weinberg equilibrium ( $p>0.05, x^{2}$ value: $\left.1.47 ; \mathrm{df}: 2\right)$. The frequencies of ICAM-1 SNPs rs3093030, rs5491 and rs5498 were also 
in Hardy-Weinberg equilibrium $\left(p>0.05, \chi^{2}\right.$ value: $0.00029 ; p>0.05, \chi^{2}$ value: 0.53 and $p>0.05, \chi^{2}$ value: 0.97 , respectively).

Table 2. Association of clinical variables with coronary artery disease (CAD)

\begin{tabular}{|c|c|c|c|c|}
\hline Clinical parameters & $\begin{array}{l}\text { Positive } \\
\text { CAD (N= } \\
339)\end{array}$ & $\begin{array}{l}\text { Negative } \\
\text { CAD (N= } \\
186)\end{array}$ & $p^{\mathrm{a}}$ & $\begin{array}{l}\text { Odds ratio } \\
(95 \% \mathrm{CI})\end{array}$ \\
\hline Gender & & & $0.004^{\mathrm{a}}$ & \\
\hline female $^{b}$ & 88 & 71 & & 1.00 \\
\hline male & 251 & 115 & & $1.76(1.18-2.63)$ \\
\hline Age (years) & & & 0.335 & \\
\hline$\leq 65^{\mathrm{b}}$ & 157 & 78 & & 1.00 \\
\hline$>65$ & 182 & 108 & & $0.84(0.57-1.22)$ \\
\hline Family history & & & 0.818 & \\
\hline negative $^{b}$ & 269 & 146 & & 1.00 \\
\hline positive & 70 & 40 & & $0.95(0.60-1.51)$ \\
\hline Smoker & & & 0.160 & \\
\hline non-active ${ }^{b}$ & 190 & 116 & & 1.00 \\
\hline active & 149 & 70 & & $1.30(0.89-1.91)$ \\
\hline $\begin{array}{l}\text { Aspirin use in the } \\
\text { past } 7 \text { days }\end{array}$ & & & $0.001^{\mathrm{a}}$ & \\
\hline negative & 194 & 139 & & 1.00 \\
\hline positive & 128 & 46 & & $1.99(1.31-3.05)$ \\
\hline $\begin{array}{l}\text { Cholesterol } \\
(\mathrm{mg} / \mathrm{dL})\end{array}$ & & & 0.803 & \\
\hline$\leq 200^{\mathrm{b}}$ & 199 & 106 & & 1.00 \\
\hline$>200$ & 106 & 77 & & $0.73(0.49-1.09)$ \\
\hline Hypertension & & & $<0.001^{\mathrm{a}}$ & \\
\hline negative ${ }^{b}$ & 86 & 75 & & 1.00 \\
\hline positive & 253 & 111 & & $1.99(1.33-2.96)$ \\
\hline Diabetes mellitus & & & $0.034^{a}$ & \\
\hline negative $^{b}$ & 194 & 124 & & 1.00 \\
\hline positive & 145 & 62 & & $1.49(1.01-2.21)$ \\
\hline $\begin{array}{l}\text { Cardiac troponin I } \\
\text { elevation }\end{array}$ & & & $<0.001^{a}$ & \\
\hline negative ${ }^{b}$ & 136 & 112 & & 1.00 \\
\hline positive & 203 & 74 & & $2.26(1.54-3.31)$ \\
\hline $\begin{array}{l}\text { Recent severe an- } \\
\text { gina (<24 hours) }\end{array}$ & & & $<0.001^{a}$ & \\
\hline negative $^{b}$ & 98 & 83 & & 1.00 \\
\hline positive & 239 & 103 & & $1.97(1.33-2.90)$ \\
\hline Risk factors $(>3)$ & & & $0.017 \mathrm{a}$ & \\
\hline negative $^{b}$ & 140 & 97 & & 1.00 \\
\hline positive & 199 & 89 & & $1.55(1.06-2.26)$ \\
\hline Stroke & & & 0.470 & \\
\hline negative $^{b}$ & 288 & 151 & & 1.00 \\
\hline positive & 34 & 22 & & $0.81(0.44-1.51)$ \\
\hline
\end{tabular}

Statistical analysis: Chi-square test

a $p<0.05$

bUsed as a reference for comparison to evaluate the odds ratio of another parameter.

We found that there is no significantly different genotypic distributions in ICAM-1SNP rs5498 (A1548G) between Taiwanese patients with CAD and those without CAD. There were also no significant difference in rs5491 (K65M) and rs3093030 (C-286T). ICAM-1 SNP rs281432 was revealed as the only significant one of which the genotypes were distributed differently between the individuals with CAD and those without CAD. Using homozygotic wild genotype CC as a comparison reference in rs281432, the homozygotic mutant genotype GG exerted the decreased risk to develop CAD ( $p=0.025$, Bonferroni test-corrected; OR: 0.40, 95\% CI: 0.19-0.82). However, the heterozygous genotype CG could not show this decreased risk $(p=1.000$, Bonferroni test-corrected; OR: 1.10, 95\% CI: 0.76-1.61). Only both mutant alleles GG in ICAM-1 SNP rs281432 could significantly protect the patients from CAD, using CC/CG as comparison references ( $p=0.006$; OR: 0.38, 95\% CI: 0.17-0.82; Table $3)$.

Table 3. Genotype distributions of the single nucleotide polymorphisms (SNPs) and haplotypes of the intercellular adhesion molecule-1 (ICAM-1) gene in patients with coronary artery disease (CAD) and those without CAD

\begin{tabular}{|c|c|c|c|c|}
\hline ICAM1 SNPs & $\begin{array}{l}\text { Positive } \\
\text { CAD } \\
(\mathrm{N}=339)\end{array}$ & $\begin{array}{l}\text { Negative } \\
\text { CAD } \\
(\mathrm{N}=186)\end{array}$ & $p^{\text {a }}$ & $\begin{array}{l}\text { Odds ratio } \\
(95 \% \mathrm{CI})\end{array}$ \\
\hline \multicolumn{5}{|l|}{ rs5491 } \\
\hline $\mathrm{AA}^{\mathrm{b}}$ & 300 & 167 & 0.556 & 1.00 \\
\hline AT & 37 & 19 & & $1.08(0.60-1.95)$ \\
\hline TT & 2 & 0 & & --- - = \\
\hline $\mathrm{AA}^{\mathrm{b}}$ & 300 & 167 & & 1.00 \\
\hline AT/TT & 39 & 19 & & $1.14(0.62-2.16)$ \\
\hline $\mathrm{AA} / \mathrm{AT}^{\mathrm{b}}$ & 337 & 186 & & 1.00 \\
\hline $\mathrm{TT}$ & 2 & 0 & & ---- \\
\hline \multicolumn{5}{|l|}{ rs5498 } \\
\hline $\mathrm{AA}^{\mathrm{b}}$ & 177 & 94 & 0.891 & 1.00 \\
\hline AG & 143 & 80 & & $0.95(0.64-1.40)$ \\
\hline GG & 19 & 12 & & $0.84(0.39-1.81)$ \\
\hline $\mathrm{AA}^{\mathrm{b}}$ & 177 & 94 & 0.713 & 1.00 \\
\hline AG/GG & 162 & 92 & & $0.94(0.64-1.36)$ \\
\hline $\mathrm{AA} / \mathrm{AG}^{\mathrm{b}}$ & 320 & 174 & 0.694 & 1.00 \\
\hline GG & 19 & 12 & & $0.86(0.39-1.99)$ \\
\hline \multicolumn{5}{|l|}{ rs281432 } \\
\hline $\mathrm{CC}^{\mathrm{b}}$ & 179 & 96 & $0.020^{\mathrm{a}}$ & 1.00 \\
\hline CG & 146 & 71 & & $1.10(0.76-1.61)$ \\
\hline GG & 14 & 19 & & $0.40(0.19-0.82)$ \\
\hline $\mathrm{CC}^{\mathrm{b}}$ & 179 & 96 & 0.794 & 1.00 \\
\hline CG/GG & 160 & 90 & & $0.95(0.66-1.39)$ \\
\hline $\mathrm{CC} / \mathrm{CG}^{\mathrm{b}}$ & 325 & 167 & 0.006 & 1.00 \\
\hline GG & 14 & 19 & & $0.38(0.17-0.82)$ \\
\hline \multicolumn{5}{|l|}{ rs3093030 } \\
\hline $\mathrm{CC}^{\mathrm{b}}$ & 222 & 113 & 0.538 & 1.00 \\
\hline CT & 101 & 64 & & $0.80(0.55-1.18)$ \\
\hline TT & 16 & 9 & & $0.90(0.39-2.11)$ \\
\hline $\mathrm{CC}^{\mathrm{b}}$ & 222 & 113 & 0.280 & 1.00 \\
\hline $\mathrm{CT} / \mathrm{TT}$ & 117 & 73 & & $0.82(0.55-1.20)$ \\
\hline $\mathrm{CC} / \mathrm{CT}^{\mathrm{b}}$ & 323 & 177 & 0.951 & 1.00 \\
\hline TT & 16 & 9 & & $0.97(0.40-2.56)$ \\
\hline $\begin{array}{l}\text { Haplotypes of } \\
\text { rs5498 and } \\
\text { rs3093030 (N=1050) }\end{array}$ & & & 0.671 & \\
\hline $\mathrm{ACb}$ & 492 & 263 & & 1.00 \\
\hline $\mathrm{AT}$ & 53 & 27 & & $1.50(0.65-1.71)$ \\
\hline GC & 5 & 5 & & $0.54(0.12-2.35)$ \\
\hline GT & 128 & 77 & & $0.89(0.65-1.22)$ \\
\hline
\end{tabular}

Statistical analysis: Chi-square or Fisher exact tests; multiple comparisons within 3 genotypes among each SNP and 4 haplotypes were adjusted using simple logistic regression model for the calculation of odds ratios and their $95 \%$ confidence intervals.

a $p<0.05$

bUsed as a reference for comparisons to evaluate the odds ratios of other genotypes. 
Because rs5498 is in linkage disequilibrium with rs3093030based on Chinese HapMap data, we established the haplotypes of ICAM-1 SNPs rs5949 and rs3093030 in order and found four types of haplotypes, AC, AT, GC and GT. Thereafter, we associated these haplotypes with CAD. However, these haplotypes were not differently distributed between the Taiwanese subjects with CAD and those without $\mathrm{CAD}$, while using haplotype $\mathrm{AC}$ as a comparison reference (Table 3 ).

Table 4. Multivariate analysis for the associations of intercellular adhesion molecule-1 (ICAM-1) single nucleotide polymorphisms and clinical characteristics with coronary artery disease (CAD)

\begin{tabular}{|c|c|c|c|c|}
\hline Clinical parameters & $\begin{array}{l}\text { Positive } \\
\text { CAD }(\mathrm{N}= \\
339)\end{array}$ & $\begin{array}{l}\text { Negative } \\
\text { CAD (N= } \\
186)\end{array}$ & $P a$ & $\begin{array}{l}\text { Adjusted odds } \\
\text { ratio } \\
(95 \% \mathrm{CI})\end{array}$ \\
\hline Gender & & & $0.018^{\mathrm{a}}$ & \\
\hline female $^{b}$ & 88 & 71 & & 1.66 \\
\hline male & 251 & 115 & & $(1.09-2.51)$ \\
\hline $\begin{array}{l}\text { Aspirin use in the } \\
\text { past } 7 \text { days }\end{array}$ & & & $0.001^{\mathrm{a}}$ & \\
\hline negativeb & 194 & 139 & & 1.00 \\
\hline positive & 128 & 46 & & $2.05(1.33-3.14)$ \\
\hline Hypertension & & & $<0.001^{a}$ & \\
\hline negative ${ }^{b}$ & 86 & 75 & & 1.00 \\
\hline positive & 253 & 111 & & $2.15(1.42-3.25)$ \\
\hline $\begin{array}{l}\text { Cardiac troponin I } \\
\text { elevation }\end{array}$ & & & $<0.001^{a}$ & \\
\hline negative & 136 & 112 & & 1.00 \\
\hline positive & 203 & 74 & & $2.18(1.47-3.24)$ \\
\hline $\begin{array}{l}\text { Recent severe } \\
\text { angina ( }<24 \text { hours) }\end{array}$ & & & $0.001^{\mathrm{a}}$ & \\
\hline negative ${ }^{b}$ & 98 & 83 & & 1.00 \\
\hline positive & 239 & 103 & & $1.97(1.31-2.95)$ \\
\hline rs281432 & & & $0.016^{\mathrm{a}}$ & \\
\hline $\mathrm{CC} / \mathrm{CG}^{\mathrm{b}}$ & 325 & 167 & & 1.00 \\
\hline GG & 14 & 19 & & $0.39(0.18-0.84)$ \\
\hline
\end{tabular}

Multivariate analysis for the associations of the significant univariate clinical variables and ICAM-1 SNP rs281432 with CAD

We further used the multivariate method to analyze the associations of the significant univariate clinical variables, including male gender, aspirin use in the past 7 days, hypertension, diabetes mellitus, cardiac troponin I elevation, severe angina in the recent 24 hours and $>3$ risk factors, as well as ICAM-1 SNP rs281432 with CAD by logistic regression model. We found that the patients with both mutant alleles GG could decreased the risk of CAD ( $p=0.016$; OR: 0.39, 95\% CI: 0.18-0.84; Table 4), using CC/CG as a reference (GG as a reference; the OR of CC/CG: 2.56, 95\% CI: 1.19-5.56). Other factors which could affect the development of CAD included male gender ( $p=0.018$; OR: $1.66,95 \%$ CI: $1.09-2.51)$, aspirin use in the past 7 days ( $p=0.001$; OR: $2.05,95 \%$ CI: $1.33-3.14)$, hypertension ( $p<0.001$; OR: 2.15, 95\% CI: 1.42-3.25), serum cardiac troponin I elevation $(p<0.001$; OR: 2.18,

95\% CI: 1.47-3.24) and severe angina in recent 24 hours ( $p=0.001$; OR: $1.97,95 \%$ CI: $1.31-2.95)$.

\section{The associations of demographic features and clinical variables with the only significant ICAM-1 SNP rs281432 in Taiwanese patients with CAD}

In the patients with $\mathrm{CAD}$, we associated the demographic features and clinical variables with ICAM-1 SNPrs281432. These CAD patients were subdivided into the group with rs231432 GG and another group with CC/CG. We found that there are no significantly different demographic and clinical features among these two groups (Table 5). This means that rs281432 is an independent factor that influences the development of CAD.

Table 5. The comparisons of demographic features and clinical variables between the single nucleotide polymorphism of intercellular adhesion molecule-1rs281432 GG and CC/CG groups in patients with coronary artery disease (CAD)

\begin{tabular}{|c|c|c|c|c|}
\hline Clinical parametersa & rs281432 & rs281432 & $P$ & Odds ratio \\
\hline & & & & \\
\hline Gender & & & 0.336 & \\
\hline femaleb & 7 & 152 & & 1.00 \\
\hline male & 24 & 342 & & $1.52(0.62-4.28)$ \\
\hline Age (years) & & & 0.125 & \\
\hline$\leq 65^{b}$ & 18 & 217 & & 1.00 \\
\hline$>65$ & 13 & 277 & & $0.57(0.25-1.25)$ \\
\hline Family history & & & 0.822 & \\
\hline negative $^{b}$ & 25 & 390 & & 1.00 \\
\hline positive & 6 & 104 & & $0.90(0.29-2.33)$ \\
\hline Smoker & & & 0.688 & \\
\hline non-active ${ }^{b}$ & 17 & 289 & & 1.00 \\
\hline active & 14 & 205 & & $1.16(0.52-2.57)$ \\
\hline Aspirin use in the past 7 days & & & 0.285 & \\
\hline negative $^{b}$ & 21 & 312 & & 1.00 \\
\hline positive & 7 & 167 & & $0.62(0.22-1.56)$ \\
\hline Cholesterol & & & 0.289 & \\
\hline$\leq 200^{b}$ & 21 & 284 & & 1.00 \\
\hline$>200$ & 10 & 205 & & $0.66(0.27-1.50)$ \\
\hline Hypertension & & & 0.317 & \\
\hline negative ${ }^{b}$ & 12 & 149 & & 1.00 \\
\hline positive & 19 & 345 & & $0.68(0.31-1.59)$ \\
\hline Diabetes mellitus & & & 0.501 & \\
\hline negative $^{b}$ & 17 & 301 & & 1.00 \\
\hline positive & 14 & 193 & & $1.28(0.57-2.84)$ \\
\hline Cardiac troponin I elevation & & & 0.177 & \\
\hline negative ${ }^{b}$ & 11 & 237 & & 1.00 \\
\hline positive & 20 & 257 & & $1.68(0.75-3.96)$ \\
\hline $\begin{array}{l}\text { Recent severe angina }(<24 \\
\text { hours) }\end{array}$ & & & 0.203 & \\
\hline negative $^{b}$ & 14 & 167 & & 1.00 \\
\hline positive & 17 & 325 & & $0.62(0.28-1.41)$ \\
\hline Risk factors $(>3)$ & & & 0.998 & \\
\hline negative $^{b}$ & 14 & 223 & & 1.00 \\
\hline positive & 17 & 271 & & $1.00(0.45-2.24)$ \\
\hline Stroke & & & 0.183 & \\
\hline negative $^{\mathrm{b}}$ & 27 & 412 & & 1.00 \\
\hline positive & 1 & 55 & & $0.28(0.01-1.76)$ \\
\hline
\end{tabular}




\section{Discussion}

Our study revealed that only the subjects who have ICAM-1 SNP rs281432 homozygotic mutant GG significantly protect themselves from suffering CAD. The subjects with rs 281432 CC/CG were more susceptible to CAD than those with GG. Other ICAM-1 SNPs, including rs5491, rs5498 and rs3093030, were not associated the development of CAD in Taiwanese patients who received elective coronary angiography due to positive noninvasive tests. The ICAM-1 gene was demonstrated to have functional activity and its genetic polymorphisms have been suggested to affect mRNA splicing patterns that modify cell-cell interactions and influence inflammatory response [22]. Additionally, the variants might have possible functional value in the etiology of atherosclerosis [15].

The association of rs281432 with CAD is not demonstrated up to date. However, its implication with disease has been reported. They showed that ICAM-1 gene SNP rs281432 (C8823G) confers susceptibility to the type 1 diabetes and is probably associated with diabetic nephropathy in Swedish Caucasians [13]. It was also revealed that ICAM-1 rs281432 may be applied as a factor to predict the clinical stage in oral squamous cell carcinoma patients [23].

The common ICAM-1 SNP being correlated with CAD is rs5498 (A1548G, K469E). K469E polymorphism of ICAM-1 that plays a role in atherosclerotic pathogenesis was demonstrated to be related to coronary slow flow [24]. This non-synonymous rs5498 locates three bases upstream of the splicing site in exon 6 and affects the splicing of ICAM-1 mRNA [22]. This splicing site produces either the full-length ICAM-1 (ICAM-1-L) or a truncated isoform (ICAM-1-S), which is soluble and has altered dimerization and signal transduction properties [7]. Inflammatory factors are the major mechanisms in the formation and progression of atherosclerosis [25]. One important inflammatory factor, ICAM-1, is a cell surface glycoprotein, which is released from endothelial cells, macrophages, and lymphocytes and may play an important role in the formation of atherosclerotic plaques because it mediates activation of endothelial cells, triggers inflammation, and causes transmigration and adhesion of leukocytes to vascular basal membranes [10]. Nevertheless, our study could not reveal an association of ICAM-1 rs5498 with CAD significantly. In agreement with this finding, no significant difference was also observed in the distribution of rs5498 genotypes in ICAM-1 gene between cases and controls by another study [26]. A number of SNPs may be silent with no direct effect on gene products. However, by virtue of linkage disequilibrium, such as rs5498 and rs3093030 in this study, which presents across the human genome, haplotypes can still be used as genetic markers to locate adjacent functional variants that contribute to disease. Although we further established the haplotypes of rs5498 and rs3093030, we still could not find an association of these haplotypes with CAD.

In addition to the relationship of ICAM-1 SNP rs281432 with CAD, our study found that male gender, aspirin use in the past 7 days, hypertension, diabetes mellitus, serum cardiac troponin I elevation, severe agina in recent 24 hours and more than 3 risk factors are important factors concerned with CAD using univariate analysis. Multivariate analysis further demonstrated that only male, aspirin use in the past 7 days, hypertension, cardiac troponin I elevation, severe angina in recent 24 hours and ICAM-1 rs281432 CC/CG increase the risk of the development of CAD. It has been demonstrated that the incidence of CAD was markedly lower in women $<60$ years of age than in older women. After 60 years of age, the rate of $\mathrm{CAD}$ increased and reached the rate seen among men by the 8th decade of life [27].It was revealed that systolic-diastolic hypertension may increase the hazard ratio of 2.47 (95\% CI: 2.16-2.82) for the development of CAD [28]. The hazard ratio of CAD has been showed up to 3.46 (95\% CI: 1.59-7.54) in women with diabetes mellitus but not in male [29]. In contrast, our univariate analysis found that the risk of CAD is increased to 1.66 only in men with diabetes mellitus ( $p=0.033,95 \% \mathrm{CI}$ : 1.02-2.73), whereas this risk was not found in men and women with diabetes mellitus based on multivariate analysis (data not showed). Although continuous elevation of serum cholesterol may lead to its accumulation within the artery wall, subsequent inflammatory response, and formation of atherosclerotic plaques [5], this study did not show the difference of the serum cholesterol concentrations between the patients with CAD and without CAD. Another important biomarker which predicted CAD in this study was elevated serum troponin I. Serum cardiac troponin levels have been purposed to be essential for diagnostic assessment and risk prediction in patients with symptoms of unstable coronary artery disease [30]. Cardiac Troponin I even reflects the myocardial injury because it is a component of the contractile apparatus of myocardial cells, which is expressed almost exclusively in the heart [31].

One limitation of the study is that the participants were male and female subjects who received elective coronary angiography because of positive noninvasive tests. Based on the ethical guidelines, it was impossible to do routine coronary angiography for the healthy individuals who were regarded as controls. Therefore, this may affect the types of ICAM-1 SNP which were related to the development 
of CAD. However, our findings that ICAM-1 SNP rs281432 affected the development of CAD are especially recommended applicable to the Taiwanese subjects who have heart problems and seek for medical help because of positive noninvasive tests. Another limitation is that the cohort is fairly small for studying CAD. It only included 339 subjects with CAD and 186 without CAD. It is necessary that more individuals are recruited to associate the ICAM-1 SNPs with CAD susceptibility in Taiwanese subjects in the future. Furthermore, the level of vascular ICAM-1 gene of CAD patients versus non-CAD control to see how SNP rs281432, in particular, that carrying homozygotic GG mutation, affect ICAM-1 in atherosclerosis is worth for further investigation, which will be included in our future work.

In this study, we also related the ICAM-1 SNP rs281432 to the demographic features and clinical variables in the patients with CAD. We found that there is no association between these factors and rs281432. This implies that ICAM-1 SNP rs281432 is an independent factor to predict the development of CAD. To our knowledge, this study is the first comprehensive one to associate ICAM-1 SNP rs231432 (C8823G) with CAD in Taiwanese subjects. Moreover, we found that ICAM-1 SNP rs281432 homozygotic mutant GG can reduce the susceptibility to the CAD.

\section{Competing Interests}

The authors have declared that no competing interest exists.

\section{References}

1. [No authors listed]. WHO publishes definitive atlas on global heart disease and stroke epidemic. Indian J Med Sci 2004, 58:405-406.

2. Ross R, Faggiotto A, Bowen-Pope D, Raines E: The role of endothelial injury and platelet and macrophage interactions in atherosclerosis. Circulation 1984, 70:III77-82.

3. Pencina MJ, D'Agostino RB, Sr., Larson MG, Massaro JM, Vasan RS: Predicting the 30-year risk of cardiovascular disease: the framingham heart study. Circulation 2009, 119:3078-3084.

4. Greenland P, Alpert JS, Beller GA, Benjamin EJ, Budoff MJ, Fayad ZA, Foster E, Hlatky MA, Hodgson JM, Kushner FG, et al: 2010 ACCF/AHA guideline for assessment of cardiovascular risk in asymptomatic adults: a report of the American College of Cardiology Foundation/American Heart Association Task Force on Practice Guidelines. J Am Coll Cardiol 2010, 56:e50-103.

5. Libby P: What have we learned about the biology of atherosclerosis? The role of inflammation. Am J Cardiol 2001, 88:3J-6J.

6. Nakashima Y, Raines EW, Plump AS, Breslow JL, Ross R: Upregulation of VCAM-1 and ICAM-1 at atherosclerosis-prone sites on the endothelium in the ApoE-deficient mouse. Arterioscler Thromb Vasc Biol 1998, 18:842-851.

7. Hubbard AK, Rothlein R: Intercellular adhesion molecule-1 (ICAM-1) expression and cell signaling cascades. Free Radic Biol Med 2000, 28:1379-1386.

8. Hopkins AM, Baird AW, Nusrat A: ICAM-1: targeted docking for exogenous as well as endogenous ligands. Adv Drug Deliv Rev 2004, 56:763-778.

9. Hayflick JS, Kilgannon P, Gallatin WM: The intercellular adhesion molecule (ICAM) family of proteins. New members and novel functions. Immunol Res 1998, 17:313-327.

10. Blankenberg S, Barbaux S, Tiret L: Adhesion molecules and atherosclerosis. Atherosclerosis 2003, 170:191-203.

11. Poston RN, Haskard DO, Coucher JR, Gall NP, Johnson-Tidey RR: Expression of intercellular adhesion molecule-1 in atherosclerotic plaques. Am J Pathol 1992, 140:665-673.

12. Ji $\mathrm{YN}$, Wang $\mathrm{Q}$ Zhan $\mathrm{P}$. Intercellular adhesion molecule 1 gene K469E polymorphism is associated with coronary heart disease risk: a meta-analysis involving 12 studies. Mol Biol Rep 2012, 39:6043-6048.
13. Ma J, Mollsten A, Prazny M, Falhammar $\mathrm{H}$, Brismar $\mathrm{K}$, Dahlquist $\mathrm{G}$, Efendic $\mathrm{S}$, Gu HF: Genetic influences of the intercellular adhesion molecule 1 (ICAM-1) gene polymorphisms in development of Type 1 diabetes and diabetic nephropathy. Diabet Med 2006, 23:1093-1099.

14. Nejentsev S, Laaksonen M, Tienari PJ, Fernandez O, Cordell H, Ruutiainen J, Wikstrom J, Pastinen T, Kuokkanen S, Hillert J, Ilonen J: Intercellular adhesion molecule-1 K469E polymorphism: study of association with multiple sclerosis. Hum Immunol 2003, 64:345-349.

15. Gaetani E, Flex A, Pola R, Papaleo P, De Martini D, Pola E, Aloi F, Flore R, Serricchio M, Gasbarrini A, Pola P: The K469E polymorphism of the ICAM-1 gene is a risk factor for peripheral arterial occlusive disease. Blood Coagul Fibrinolysis 2002, 13:483-488.

16. Hsu LA, Chang CJ, Wu S, Teng MS, Chou HH, Chang HH, Chang PY, Ko YL: Association between functional variants of the ICAM1 and CRP genes and metabolic syndrome in Taiwanese subjects. Metabolism 2010, 59:1710-1716.

17. Kim K, Brown EE, Choi CB, Alarcon-Riquelme ME, Kelly JA, Glenn SB, Ojwang JO, Adler A, Lee HS, Boackle SA, et al: Variation in the ICAM1-ICAM4-ICAM5 locus is associated with systemic lupus erythematosus susceptibility in multiple ancestries. Ann Rheum Dis 2012, 71:1809-1814.

18. Kammerer S, Roth RB, Reneland R, Marnellos G, Hoyal CR, Markward NJ, Ebner F, Kiechle M, Schwarz-Boeger U, Griffiths LR, et al: Large-scale association study identifies ICAM gene region as breast and prostate cancer susceptibility locus. Cancer Res 2004, 64:8906-8910.

19. Chobanian AV, Bakris GL, Black HR, Cushman WC, Green LA, Izzo JL, Jr., Jones DW, Materson BJ, Oparil S, Wright JT, Jr., Roccella EJ: Seventh report of the Joint National Committee on Prevention, Detection, Evaluation, and Treatment of High Blood Pressure. Hypertension 2003, 42:1206-1252.

20. NCEP. Third Report of the National Cholesterol Education Program (NCEP) Expert Panel on Detection, Evaluation, and Treatment of High Blood Cholesterol in Adults (Adult Treatment Panel III) final report. Circulation 2002, 106:3143-3421.

21. Ogawa Y, Hirakawa K, Nakata B, Fujihara T, Sawada T, Kato Y, Yoshikawa K, Sowa M: Expression of intercellular adhesion molecule-1 in invasive breast cancer reflects low growth potential, negative lymph node involvement, and good prognosis. Clin Cancer Res 1998, 4:31-36.

22. Iwao M, Morisaki H, Morisaki T: Single-nucleotide polymorphism g.1548G > A (E469K) in human ICAM-1 gene affects mRNA splicing pattern and TPA-induced apoptosis. Biochem Biophys Res Commun 2004, 317:729-735.

23. Lin CW, Chuang CY, Tang CH, Chang JL, Lee LM, Lee WJ, Chow JM, Yang SF, Chien MH: Combined effects of icam-1 single-nucleotide polymorphisms and environmental carcinogens on oral cancer susceptibility and clinicopathologic development. PLoS One 2013, 8:e72940.

24. Gazi E, Barutcu A, Altun B, Temiz A, Bekler A, Urfali M, Silan F, Colkesen Y, Ozdemir O: Intercellular adhesion molecule-1 K469E and angiotensinogen T207M polymorphisms in coronary slow flow. Med Princ Pract 2014, 23:346-350.

25. Libby $\mathrm{P}$, Theroux P: Pathophysiology of coronary artery disease. Circulation 2005, 111:3481-3488.

26. Sarecka-Hujar B, Zak I, Krauze J: Interactions between rs5498 polymorphism in the ICAM1 gene and traditional risk factors influence susceptibility to coronary artery disease. Clin Exp Med 2009, 9:117-124.

27. Blum A, Blum N: Coronary artery disease: Are men and women created equal? Gend Med 2009, 6:410-418.

28. Arima H, Murakami Y, Lam TH, Kim HC, Ueshima H, Woo J, Suh I, Fang X, Woodward M: Effects of prehypertension and hypertension subtype on cardiovascular disease in the Asia-Pacific Region. Hypertension 2012, 59:1118-1123.

29. Doi $Y$, Ninomiya $T$, Hata J, Fukuhara $M$, Yonemoto $K$, Iwase $M$, Iida $M$, Kiyohara Y: Impact of glucose tolerance status on development of ischemic stroke and coronary heart disease in a general Japanese population: the Hisayama study. Stroke 2010, 41:203-209.

30. Thygesen K, Alpert JS, Jaffe AS, Simoons ML, Chaitman BR, White HD, Katus HA, Lindahl B, Morrow DA, Clemmensen PM, et al: Third universal definition of myocardial infarction. Circulation 2012, 126:2020-2035.

31. Thygesen K, Alpert JS, White HD: Universal definition of myocardial infarction. Eur Heart J 2007, 28:2525-2538. 